\title{
A experiência do adoecimento neurológico não diagnosticado: um estudo exploratório
}

The experience of non-diagnosed neurological illness: an exploratory study

Fernanda Tomie Icassati Suzuki; Mariolga Teldeschi Lima; Nadia Vitorino Vieira

Universidade Federal do Estado de São Paulo

\begin{abstract}
RESUMO:
Para uma pessoa acometida por sintomas que a levam a crer que esteja doente, conhecer o nome da doença que lhe causa sofrimento é algo de grande importância e que muda a maneira como ela se relaciona com seu adoecimento. Frente à escassez de estudos que abordem qualitativamente como a ausência de nomeação de uma doença pode influenciar a vivência de adoecimento próprio ou de um familiar, buscamos explorar essa questão. Utilizamos a metodologia da História Oral para construir entrevistas com pacientes e familiares de pacientes internados na enfermaria de Neurologia do Hospital São Paulo. Posteriormente, as entrevistas foram analisadas por meio da análise de conteúdo proposta por Laurence Bardin. Foram obtidas categorias temáticas relacionadas às questões de causalidade, culpa, dificuldade de acesso a recursos, expectativas ambivalentes e sentimento de esperança ao chegar no hospital. Esses temas se mostraram de acordo com a experiência prática e com a literatura estudada.
\end{abstract}

Palavras-chave: psicologia hospitalar; psicologia da saúde; diagnóstico

\section{ABSTRACT:}

For a person with symptoms that leads him or her to believe to be ill, knowing the name of the disease that causes suffering is very important and changes the way that he or she relates to being ill. Facing the scarcity of studies that approach qualitatively how the absence of naming of a disease may influence the experience of one's own illness or that of a family member, we look to explore this question. We used the Oral Story method to elaborate interviews with patients admitted at the Neurology ward at the Hospital São Paulo and their family members. Afterwards, the interviews were analyzed through Bardin's content analysis. We obtained theme categories that relate to the matters of causality, blame, difficulty of access to resources, ambivalent expectations and feelings of hope when admitted to the hospital. These themes were in accordance with the practical experience and the studied literature.

Key-words: Hospital psychology; health psychology; diagnosis.

DOI: 10.12957/mnemosine.2021.61868 
Quero aqui enfatizar que praticamente sempre este é o principal e mais imediato problema; a necessidade de um nome para a doença, um diagnóstico. É apenas na segunda instância que o paciente pede por terapia, isto é, o que pode ser feito para aliviar seus sofrimentos por um lado e as restrições e privações provocadas pela doença por outro. (BALINT, 1975: 22)

$\mathrm{O}$ ato de se diagnosticar uma doença de certa forma organiza a experiência de adoecimento de um indivíduo, mas não a inaugura (BALINT, 1975). Antes do encontro médico-paciente, o sujeito já vivencia sintomas com os quais não está acostumado e começa a suspeitar, por vezes junto de familiares e pessoas próximas, que algo está errado consigo mesmo (MORSE et alii., 1991). É a crença do sujeito (e/ou de seus familiares) de que a causa desse mal-estar é de ordem médica, e não de qualquer outra ordem, que o leva a buscar o conhecimento e a autoridade do médico. Este encontro também se dá graças à inabilidade do sujeito leigo de traduzir seu desconforto em um diagnóstico, e é o poder de explicação do diagnóstico que ele busca por meio do conhecimento médico (JUTEL, 2011)

A importância conferida pelo (agora) paciente à nomeação de sua doença não deve ser menosprezada. Pode-se argumentar que o objetivo do diagnóstico seja justamente o de propor uma terapia, o que não deixa de ser verdadeiro para o médico e, em muitos casos, de fato aparece como uma aflição expressa por pacientes e seus familiares. Segundo Balint (1975), no entanto, a primeira necessidade do paciente que busca ajuda médica na maioria das vezes não é, como podem supor os médicos, o estabelecimento de uma conduta terapêutica, mas a nomeação de sua doença, ou seja, “(...) a função do diagnóstico é a de suprir o nome pelo qual este algo [a doença] desagradável, malevolente e assustador possa ser chamado, pensado e talvez elaborado." (BALINT, 1975: 36). Nota-se aí, portanto, a importância do nome da doença para a maneira como o paciente e sua família irão enfrentar essa experiência de adoecimento.

É possível supor que a ausência de um diagnóstico não seja uma experiência tão emocionalmente desgastante quanto a presença de um diagnóstico desfavorável. No entanto, não é o que apontam pesquisas feitas no contexto do diagnóstico de câncer. Segundo Flory et Lang (2011), em uma pesquisa em que foram medidos parâmetros de bem-estar psicológico em uma sala de espera para diferentes procedimentos radiológicos, constatou-se que mulheres que aguardavam uma biópsia de mama apresentavam nível de ansiedade significativamente maior do que aquelas que aguardavam procedimentos invasivos para tratamento de tumores benignos, bem como de tumores malignos. Nota-se no estudo, portanto, que a situação de incerteza diante da possibilidade de diagnóstico de câncer gerou maior ansiedade do que a situação de um diagnóstico de câncer já confirmado nas mulheres que estavam passando por um tratamento. 
Esses achados vão ao encontro do que afirma Schiller (2000: 130):"Em qualquer tempo, em qualquer cultura, toda pessoa deseja dar à sua doença um nome e um sentido. A angústia pela ausência de um diagnóstico é maior do que a angústia que se vive após o esclarecimento das causas e dos sintomas, ainda que eles revelem uma patologia grave."

O poder da autoridade médica no processo de investigação diagnóstica foi descentralizado na atualidade, devido a uma série de mudanças associadas, principalmente, ao acesso às informações médicas disponíveis ao indivíduo leigo (JUTEL, 2015). O presente trabalho, no entanto, propõe-se a explorar a experiência do paciente e seus familiares no processo de investigação diagnóstica especificamente no âmbito hospitalar, onde a figura do médico ocupa uma centralidade maior do que no contexto domiciliar, em uma situação não agudizada. A hospitalização pressupõe que o paciente apresentou algum motivo para ser internado, seja pela magnitude/agudeza de seus sintomas, seja pela necessidade de se realizar exames e/ou tratamentos específicos. A vida cotidiana é momentaneamente suspensa e substituída por uma vida de permanência no hospital, fora do âmbito familiar, onde o sujeito é destituído de seus papéis sociais e é submetido à rotina padronizada da instituição e aos cuidados dos profissionais de saúde (ROMANO, 2007). Durante a hospitalização, portanto, o adoecimento tende a se tornar um fator central na vida do sujeito internado.

Observa-se que nos serviços de neurologia hospitalar há casos em que a investigação diagnóstica pode prolongar-se por algum tempo, dada a singularidade da apresentação dos sintomas em alguns pacientes. Chowdhury et alii. (2014) encontraram que, dentre os pacientes avaliados por neurologistas em um hospital geral universitário, $9 \%$ deles não tiveram um diagnóstico definido após a primeira avaliação clínica. Em um estudo conduzido em contexto ambulatorial, Aitchison et alii. (2020) encontraram que, dentre 200 casos avaliados por três neurologistas, houve concordância diagnóstica total em 111 casos, concordância entre dois dos três especialistas em 62 casos e discordância total em 27 casos.

Kornelsen, et alii. (2015) conduziram um estudo que explorou a experiência de pacientes vivendo com sintomas físicos sem explicação médica (em inglês, Medically Unexplained Physical Symptoms, ou MUPS). Os principais achados referentes ao período de investigação diagnóstica indicaram a prevalência de altos níveis de ansiedade, a crença de que o diagnóstico poderia gerar opções de tratamento, a importância conferida à nomeação do diagnóstico como uma maneira de validar socialmente sua doença e o papel central da qualidade da relação estabelecida entre paciente e médico. 
Diante desse cenário, nos pareceu interessante propor uma tentativa de compreender um pouco melhor como é a vivência de pacientes e familiares de pessoas que, durante uma internação, apresentam sinais e sintomas de um adoecimento neurológico que, no entanto, ainda não foi diagnosticado. Optamos por incluir familiares como colaboradores, uma vez que a experiência do adoecimento não envolve apenas a díade paciente-médico, mas acomete também de maneira significativa os familiares e pessoas próximas ao paciente no que diz respeito à vivência de sofrimento, dor e ameaça à vida (MORSE et alii., 1991).

A metodologia da História Oral foi utilizada, como um caminho privilegiado para o contato com a subjetividade e a maneira como os colaboradores da pesquisa elaboraram a experiência vivida (COSTA, 2015). Nesse sentido, mais do que um levantamento dos fatos e acontecimentos associados à questão investigada, nos interessou o próprio convite à narrativa oral, como um processo de interpretação e atribuição de sentidos à realidade (PORTELLI, 2003, SOUZA, 2017). Buscamos, com esse percurso, poder contribuir para a compreensão do fenômeno em si, na esperança de fornecer dados para os profissionais de saúde que cuidam dessas pessoas, bem como reconhecer, legitimar e ouvir a narrativa de pessoas que de alguma forma vivem o adoecimento não nomeado, apostando no poder terapêutico do próprio ato narrativo, que permite a emergência de significados para a doença e para o sofrimento (BENEDETTO et alli., 2010).

\section{Método}

Foi realizado um estudo qualitativo, exploratório transversal baseado na história oral de vida desses pacientes e seus familiares e análise de conteúdo dos resultados obtidos de acordo com a proposta de Bardin (2011).

O projeto de pesquisa foi submetido ao Comitê de Ética em Pesquisa da UNIFESP/EPM e aprovado sob o número de Certificado de Apresentação para Apreciação Ética 47406115.3.0000.5505.

Os colaboradores foram selecionados entre pacientes e familiares de pacientes internados na Unidade de Internação de Neurologia do Hospital São Paulo no período entre Julho e Outubro de 2015. Para a inclusão no estudo, foram selecionados pacientes que se mostraram cientes da indefinição de seu diagnóstico ou de seu familiar e que aceitaram participar do estudo. Não foram convidados a participar aqueles que, após uma abordagem inicial da pesquisadora, foram considerados impossibilitados de compreender e significar a experiência de adoecimento própria ou de seu familiar ou de travar diálogo com fluência, fosse 
por déficit cognitivo ou alteração psiquiátrica. Foram realizadas quatro entrevistas, dentre elas três com familiares de pacientes e uma com um paciente internado.

Foram realizadas entrevistas abertas com os colaboradores dentro da tradição da História Oral de Vida, aqui entendida como “[...] uma prática de apreensão de narrativas feita através do uso de meios eletrônicos e destinada a: recolher testemunhos, promover análises de processos sociais do presente, e facilitar o conhecimento do meio imediato." (MEIHY et alii., 2007: 18).

O disparador para a fala dos participantes foi um esclarecimento inicial sobre o interesse da pesquisadora por ouvir sobre a experiência de se estar internado (ou acompanhando um familiar que o estivesse) sem um diagnóstico definido. Ele era, então, seguido por um convite para que o participante falasse sobre sua experiência nesse contexto. As entrevistas foram audiogravadas e, posteriormente, transcritas. O texto resultante da transcrição foi então transcriado, ou seja, submetido a um processo de tradução da linguagem oral para a linguagem escrita, de acordo com a proposta de Meihy et alii. (2007). Considerou-se esse um processo que, assim como a tradução entre diferentes idiomas, implica um certo nível de criação para se atingir um resultado mais fiel e representativo, o que se perde em uma transposição estritamente literal do texto (PORTELLI, 2003). Dessa forma foram obtidos textos escritos em primeira pessoa a partir da transcrição das entrevistas, os quais foram enviados aos colaboradores para conferência, com o intuito de salvaguardar a fidelidade do conteúdo transmitido originalmente. Dois dos colaboradores ratificaram os textos finais. Não se obteve uma resposta dos demais colaboradores.

Os dados obtidos a partir das entrevistas de história oral de vida foram então analisados de acordo com a metodologia de Análise de Conteúdo conforme proposta por Bardin (2011). Essa metodologia indica um conjunto de procedimentos (pré-análise, exploração do material e tratamento dos resultados) que permitem uma leitura de conteúdos contidos nos discursos analisados, podendo se extrair deles categorias temáticas, conforme realizado no presente estudo.

\section{Resultados}

Dou uma pequena pista para quem quiser escutar: Não se trata de ouvir uma série de frases que enunciam algo; o que importa é acompanhar a marcha de um mostrar.

(HEIDEGGER, 1999: 252) 
A primeira colaboradora é avó de uma paciente de 25 anos, internada com sintomas de rebaixamento do nível de consciência, vômitos, soluços, turvamento visual e fraqueza, tendo sido mais tarde diagnosticada com Esclerose Múltipla. O discurso aborda o tema da culpa diversas vezes, sendo que a colaboradora oscila entre acusar a mãe da paciente de negligência e assumir uma responsabilidade pelo adoecimento da neta, por não a ter socorrido antes. A avó revela uma sensação de ter subestimado as queixas da neta e estabelece um vínculo entre o adoecimento da paciente e outras situações geradoras de sofrimento em sua história de vida. Expressa receio de que possa ser confirmada a hipótese diagnóstica de Esclerose Múltipla, o que alimentaria seu remorso por não ter dado maior importância aos sintomas da paciente. A fala se encerra com considerações da colaboradora que expressam algumas preocupações em relação à sua própria saúde.

A segunda colaboradora é filha de uma paciente de 66 anos que vinha sofrendo quedas há cerca de um mês, tendo sido mais tarde diagnosticada com Síndrome de Guillain-Barré, o que explicaria uma fraqueza dos membros e quedas frequentes. A colaboradora descreve uma sensação de impotência e de humilhação diante do período em que buscou atendimento médico para sua mãe por não se sentir devidamente contemplada nos cuidados oferecidos pelos profissionais. Ela conta que foi apenas em uma consulta particular que as queixas foram devidamente ouvidas, legitimadas e a paciente encaminhada para exames e cuidados adequados, tendo então acesso ao tratamento, após ser avalizada pelo profissional e pelos exames realizados. Além da sensação de desamparo, a colaboradora relata que a família também chegou a questionar a pertinência das queixas apresentadas pela paciente. $O$ processo médico de investigação diagnóstica e explicações etiológicas é contraposto às hipóteses familiares para o adoecimento da paciente, que giram em torno de comportamentos e hábitos inadequados e repreendidos pelos familiares próximos. A narrativa se encerra com um relato em primeira pessoa da colaboradora de ter passado por um período prolongado de investigação diagnóstica para uma condição ortopédica e estar, no momento, aguardando acesso ao tratamento cirúrgico adequado.

O terceiro colaborador é esposo de uma paciente de 62 anos internada após um AVC isquêmico. Na investigação etiológica, foram vistas, em exames de imagens, massas intracranianas, sendo que duas delas foram diagnosticadas como benignas e a outra foi mais tarde identificada como uma infecção fúngica. Desde o início, a metáfora que predomina é de um embate entre o sujeito e a doença. O colaborador se mostra otimista, mas manifesta aflição ao afirmar que, para obter a vitória, é preciso conhecer seu oponente pelo nome. Surge, aos 
poucos, um sentimento ambivalente, que oscila entre a confiança e a impotência quanto ao desfecho da situação. Essa situação se mostra geradora de sofrimento ao narrador. A fala se encerra com uma atribuição de sentido à situação que parece atuar como uma espécie de resolução para o conflito que foi posto: uma doença não nomeada é a manifestação de um espírito maligno, contra o qual é possível lutar e vencer, por meio da fé religiosa.

O quarto colaborador é um paciente de 56 anos que foi internado com dor na coluna e fraqueza na perna, tendo sido mais tarde diagnosticado com um sangramento medular relacionado a doenças pré-existentes. Ele faz um relato sobre experiências anteriores de adoecimento grave, onde já passara pela situação de desconhecer seu diagnóstico durante sua internação. Inicialmente, ressalta que o diagnóstico em si é pouco importante e que está confiante na possibilidade de seguir tocando sua vida, como das outras vezes. Entretanto, gradualmente revela um receio de receber informações desfavoráveis dos médicos e uma atitude de evitação em relação à sua condição de saúde. $\mathrm{O}$ colaborador parte, então, para considerações sobre sua finitude e a fragilidade diante dos acontecimentos da vida.

\section{Discussão}

A partir da análise das transcriações, foram observadas categorias temáticas relevantes para a observação de conteúdos que dizem respeito à vivência do adoecimento nãodiagnosticado.

\section{a) Causalidade}

Diante de uma experiência de adoecimento, há duas narrativas: a do paciente e a do médico (JUTEL, 2011). Enquanto a narrativa médica toma a doença em termos de uma alteração no organismo do paciente causada por fatores específicos e reconhecida dentro da comunidade médica, a narrativa do paciente leva em conta sua individualidade, sua cultura e sua vivência do adoecimento (MANSO, 2014).

Na fala de um mesmo colaborador, é possível acompanhar uma alternância entre as duas narrativas. Por um lado, se assume a legitimidade do discurso médico e, por outro, se introduzem também outras abordagens para a doença. Conciliam, dessa forma, ambas as narrativas, que não se apresentam como mutuamente excludentes:

"São uns nominhos complicados, as doenças! Mas é a mesma coisa que o outro médico tinha falado, então eles falaram que teriam que fazer outros exames, para ver se não 
eram outros vírus [...] A gente tem várias hipóteses do que poderia ter causado o adoecimento dela. Uma é da queda que ela sofreu, que deve ter inflamado algum órgão, ter dado alguma complicação e passado para os nervos. A gente também leu sobre medicação, e ela é danadinha; ela tomava muita medicação sem a prescrição médica. [...] E também, o não-cozimento, ou o alimento ficar um pouco cru, que pode causar isso. [...] Tem várias hipóteses. E ela acaba contribuindo para todas elas. Eu já até falei para ela que é uma lição que ela está tendo. Nós vamos aprendendo, não vamos fazer mais certas coisas."

Nas situações em que a etiologia do adoecimento de um indivíduo não é clara, aspectos e elementos neutros de sua vida são imbuídos de uma suposta capacidade de exacerbação da doença (MISHEL, 1990). Segundo Jutel (2011), o diagnóstico fornece estrutura, definindo quais elementos são considerados reais, válidos ou significativos e quais são considerados imaginados, simulados ou insignificantes do ponto de vista médico.

A maior parte dos colaboradores lançou mão de um modelo racional para explicar a origem do adoecimento (LAPLANTINE, 1986, apud FIGUEIREDO, 2007), uma vez que o associam a causas orgânicas. Foi observada, em menor frequência, a recorrência ao modelo benéfico/maléfico (LAPLANTINE, 1986, apud FIGUEIREDO, 2007), que atribui a doença a forças benéficas ou maléficas, que interferem no organismo.

No caso da entrevista 3 , onde o esposo da paciente atribui o adoecimento sem nome a um espírito maligno, isso fica claro e ilustra a afirmação de Balint (1975: 35): "Em outras palavras, estar doente é ainda frequentemente pensado, e é certamente sentido, como ser possuído por algum demônio, e é crença geral, não apenas entre os pacientes, que o demônio possa ser expulso apenas pelo fato de se conhecer seu nome."

\section{b) Culpa}

Duas colaboradoras abordaram de maneira significativa sentimentos de culpa relacionados à experiência narrada. Ambas iniciam suas falas atribuindo a outras pessoas grande parte do sofrimento provocado pela história de adoecimento das pacientes. Entretanto, chegam gradualmente à confissão do próprio sentimento de culpa por terem, em algum momento, subestimado as queixas referidas por suas familiares. 
Em ambos os casos, há um relato de diversas consultas médicas antes da internação hospitalar, onde o quadro apresentado pelas pacientes não foi considerado significativo, e tratado apenas com intervenções voltadas para amenizar sintomas.

As condições de agravo à saúde carregam intrinsecamente conteúdos de culpa, que são amortizados através de um contrato implícito estabelecido entre o médico e o paciente (HILLMAN, 2014), mas os sintomas que não são facilmente encaixados em uma categoria diagnóstica, ainda que sejam devidamente levados em consideração pelos médicos, podem com frequência prejudicar o estabelecimento desse contrato. Essa experiência pode estar relacionada à crença de que os sintomas tenham sido produzidos mentalmente ou a um questionamento quanto à legitimidade das queixas do paciente (TRUNDLE, 2014).

Nas sociedades ocidentais de tradição cristã, é corrente a associação entre adoecimento e punição ou expiação de conteúdos relacionados ao sentimento de culpa (AQUINO et alii., 2007, MANSO, 2014). Nesse sentido, cabe ressaltar ainda uma convergência entre as duas entrevistas supracitadas: após descreverem sentimentos de culpa, ambas as colaboradoras concluem suas falas fazendo referência a preocupações, dificuldades e ameaças à própria saúde, estabelecendo, por meio da sequência discursiva, uma relação entre o sentimento de culpa e a preocupação com a própria saúde.

\section{c) Acesso a Recursos}

No modelo médico tradicional, o paciente busca o profissional relatando um conjunto de sinais e sintomas que serão traduzidos pelo médico em uma categoria que reconhece e legitima socialmente sua doença (MANSO, 2014). O diagnóstico é, portanto, a porta de entrada da experiência do adoecimento no mundo médico, garantindo, dessa forma, acesso não somente ao tratamento em si, mas ao reconhecimento, benefícios e legitimidade do sofrimento do paciente (JUTEL, 2011, TRUNDLE et alli., 2014). Esse tema emerge entre os discursos dos colaboradores, que falam sobre a ansiedade para que se possa ter acesso a um tratamento certeiro:

"Para tudo quanto é doença, tem um remédio. Agora, como é que você vai tomar o remédio se você não sabe que doença que você tem?"

Longe de ser simples, a busca por acesso ao sistema de saúde é um percurso permeado por expectativas e interações imbuídas de significados socialmente compartilhados, no qual 
pacientes e familiares se veem na incumbência de justificar sua necessidade por tratamento (HILLMAN, 2014). Nas palavras de uma das colaboradoras:

“(...) você bate numa porta, bate em outra e parece que as pessoas pensam que você está brincando, eu acho que eles pensam que todo mundo gosta de estar no médico sem necessidade, sem precisão. Nossa, nesse último mês eu me senti muito humilhada, muito menosprezada".

d) Expectativas ambivalentes

O adoecimento que não tem um diagnóstico definido assume a possibilidade de uma infinidade de desfechos, e essas possibilidades se diversificam tanto mais quanto menos se sabe a respeito da doença. Durante o período de espera para o esclarecimento do quadro diagnóstico, é comum que as pessoas próximas do paciente fiquem apreensivas também e oscilem entre considerar a possibilidade de uma notícia devastadora e reassegurar-se de que essa possiblidade é improvável (MORSE et alii., 1991). A ambivalência quanto à progressão da doença pode surgir em uma só frase, como vemos na entrevista 1:

"Eu acho que não é grave, mas tudo indica que é, que pode voltar. Tudo que é na cabeça assusta, porque é a cabeça que domina todo o nosso corpo."

"Mas se Deus quiser, ela volta. Eu acredito. Será que isso aí pode repetir? Só a ressonância que pode dizer."

Segundo Amir (apud ROMANO, 2007), na falta de um diagnóstico definido, as fantasias subjetivas dos pacientes são ocupadas por sentimentos negativos de medo. As entrevistas 3 e 4 apresentam uma semelhança na maneira como os colaboradores enfaticamente negam qualquer tipo de preocupação quanto ao adoecimento a princípio, mas ao longo da entrevista começam a se contradizer e evidenciar preocupações em relação ao prognóstico da doença. Ambos formulam frases negativas ao falar de sua preocupação:

"Eu não fico preocupado com esse momento em que eles estão investigando as causas dos meus males nem me incomodo com a internação, o que quero é cuidar da minha saúde." 
"Mas eu sou uma pessoa que não me preocupo com as coisas, eu deixo as coisas acontecerem. Eu não perco o sono por nada nesse mundo.”

Medo e tristeza são emoções que, ao menos nas culturas ocidentais, homens tradicionalmente evitam expressar (JANSZ, 2000). É curioso que haja essa semelhança na maneira como os dois colaboradores do sexo masculino lidam com os receios e preocupações que a situação do adoecimento lhes causa. Os colaboradores negam no discurso manifesto qualquer tipo de preocupação, mas por isso mesmo parecem revelar um sentimento latente. A negação pode ser considerada como um fenômeno que supõe uma relação dialógica com outro discurso (GUIRADO, 2000). Dessa forma, a frase "Eu não estou preocupado" pressupõe um diálogo com a afirmação contrária. Se essa afirmação não foi diretamente inserida no diálogo pela entrevistadora, podemos supor que de alguma outra maneira o tema da preocupação foi suscitado pelo conteúdo do discurso em si.

e) Esperança ao chegar no hospital

Observa-se que, ao longo das narrativas, os colaboradores descrevem uma posição de passividade e impotência. A contrapartida é um depósito de confiança na instituição hospitalar e nos profissionais de saúde enquanto aliados nos cuidados a partir do ponto em que o caso é admitido para internação:

"Por enquanto, eu só posso aguardar, não sei o que dizer, por que segundo os médicos nem eles sabem. O que me tranquiliza é que estou sendo bem cuidado."

"Desde que ela veio para cá, eu pelo menos achei que ela ficou mais animada. E nós também. (...). Nós sentimos que pelo menos agora ela está tendo tratamento adequado para o que ela tem. (...) pelo menos a medicação de que ela precisava, ela está tomando. Então nós estamos mais animados, porque em casa mesmo, era um desânimo total e um desespero, sem saber o que tinha, o que podia fazer, nós queríamos tentar forçar ela a andar, mas tinha medo de que acontecesse algo."

“(...) a gente estava lá em São Miguel com ela e é horrível lá, não tinha médico... A gente entende, era sábado. Aí nós trouxemos ela para cá e deu certo, graças a Deus. Agradeço a todos vocês, pela atenção, eu sei que aqui é bom demais.” 
O estado incerto durante o qual o paciente não se sente bem, mas ao mesmo tempo não é considerado como alguém que está doente, pode ser estressante, de modo que a definição de um diagnóstico e o reconhecimento de que há uma doença em curso pode ser um alívio (MORSE et alii., 1991). O fato do paciente ser admitido em um hospital pode legitimar seu adoecimento, a despeito da ausência de um diagnóstico, bem como alimentar expectativas de que ele receberá os cuidados de que precisa.

Podemos concordar com Balint (1975) quando ele refere que, em geral, o que pode confortar o paciente e seus familiares diante de uma situação de incerteza não é tanto a exclusão de um diagnóstico considerado ruim, mas a nomeação e, de certa forma, dominação do que está acometendo o paciente. A experiência prática mostra, inclusive, que, diante da incerteza, o paciente pode até mesmo manter o medo de um determinado desfecho, mesmo que ele já tenha sido descartado pela equipe médica. Pudemos observar, de fato, como a ausência de diagnóstico abre espaço para uma série de hipóteses e conteúdos de culpa, além do receio quanto ao futuro incerto.

A autoridade profissional do médico está intimamente ligada à confiança que o paciente tem nos seu uso do repertório epistemológico para definir doenças (HERITAGE, 2019), de modo que a experiência prolongada de investigação diagnóstica pode provocar sentimentos de desconfiança em relação à comunidade médica (TEEL et alii., 2003).

É fato que, diante de uma situação de incerteza que não é só do paciente e sua família, mas também dos profissionais de saúde, as respostas podem não estar disponíveis. Nesse cenário, nos parece relevante o achado de Kornelsen et alii. (2015), que aponta para a importância do estabelecimento de uma relação médico-paciente que preconize uma boa comunicação, compartilhamento da tomada de decisões e a possibilidade do paciente ser ouvido.

A legitimação do sofrimento do paciente e seus familiares parece ser algo que gera algum conforto e sensação de confiança, ao menos pelo fato do paciente ter chegado à instituição hospitalar. Sabemos também que a maneira como os profissionais de saúde interagem com os pacientes e seus familiares pode legitimar ou não esse sofrimento.

O modo como o próprio profissional de saúde lida com a incerteza exerce influência sobre a elaboração feita pelo paciente diante da situação, de forma que uma visão de mundo que contemple a incerteza como um elemento natural da vida possibilita uma experiência menos 
aversiva de situações como a do adoecimento não diagnosticado (MISHEL, 1990). É necessário, portanto, reconhecer - e não recusar - a incerteza enquanto constitutiva das experiências humanas de busca de conhecimento (MORIN, 2019), como é o caso do processo de investigação diagnóstica.

O presente trabalho, que se prestou a fazer uma exploração inicial sobre a experiência de pacientes e familiares que vivenciam o adoecimento não-diagnosticado, mostra uma riqueza nesse objeto de estudo. Isso se mostra especialmente relevante para o profissional da saúde, que cotidianamente lida com incertezas geradoras de angústia. Mitigá-las nem sempre é possível ou até mesmo desejável, mas o cuidado, sim, sempre é. E não requer certezas.

\section{Considerações finais}

Durante o período de elaboração do projeto para realização do presente estudo, uma das autoras do artigo atendeu a mãe de uma paciente que fora admitida no hospital onde se deu a coleta de dados. Em consonância com o tema estudado, a moça apresentava uma série de manifestações de agravo ao sistema nervoso, mas não tinha um diagnóstico definido. No atendimento à familiar, emerge justamente o sofrimento intenso diante dessa situação tão impactante e, ao mesmo tempo, povoada de desconhecimento. Entre prantos, a mãe faz uma pausa e busca verificar se é de fato possível expressar sua angústia, dizendo que talvez seja difícil compreender por que essa incerteza lhe causa tanto sofrimento. Como falar, narrar e ser ouvida em relação a algo que não se nomeia? Esse é um exemplo irretocável tanto da motivação para, quanto das contribuições promovidas pelas reflexões desenvolvidas no presente artigo: alguém que esteja acometido por um adoecimento repleto de desconhecimentos e incertezas deve poder ser legitimado, acolhido e cuidado. Mais do que nunca, entendemos aqui o cuidado como aquela atitude ética que integra tanto a cura, o emprego de conhecimento técnicocientífico e de respostas advindas deles, quanto o ouvir, acolher e acompanhar. E consideramos, a partir das provocações incitadas pelo estudo, a importância de se poder reconhecer e lidar com atributos humanos como a incerteza, a impotência, a dúvida e a angústia, para que possamos nos aliar com as potencialidades criativas e saudáveis de cada sujeito no seu caminho de elaboração de processos de adoecimento.

\section{Referências}


AITCHISON Chris, BLACKBURN Daniel J., KHAN Aijaz, GRÜNEWALD Richard A., JENKINS Tom M. Diagnostic and investigative approach of consultant neurologists in a real-world clinical setting: A pilot study. Int J Clin Pract, 2020.

AQUINO, Verônica Vrban; ZAGO, Márcia Maria Fontão. The meaning of religious beliefs for a group of cancer patients during rehabilitation. Rev. Latino-Am. Enfermagem, Ribeirão Preto, v.15, n.1, 2007. Disponível em $<$ http://www.scielo.br/scielo.php?script=sci_arttext\&pid=S0104$11692007000100007 \& \operatorname{lng}=$ en\&nrm=iso>, acessado em 26 de março de 2021

BALINT, Michael. O Médico, seu Paciente e a Doença. Rio de Janeiro: Atheneu, 1975

BARDIN, Laurence. Análise de Conteúdo. São Paulo: Editora 70 - Brasil, 2011

BENEDETTO Maria Auxiliadora Craice de, GARCIA Deborah, BLASCO Pablo González. Era uma vez... narrativas em medicina. Rev Bras Cuid Paliat. 3(1), 19-25, 2021

CHOWDHURY, Rajib Nayan, HASAN, Hasibul, RAHMAN, Yusuf Ur, KHAN, Shafikul Islam, HUSSAIN, Ahmed Riyad, AHSAN, Shamim. Pattern of neurological disease seen among patients admitted in tertiary care hospital. BMC Research Notes 7:202, 2014

COSTA, Otávio Barduzzi Rodrigues da. Tecendo algumas técnicas de história oral: como (re) compreender a identidade do pesquisado. Monções, 2(2), 134-154, 2015

FIGUEIREDO, Regina. Noções de saúde, doença e cura como construções sócio-culturais. BIS, Bol. Inst. Saúde (Impr.), São Paulo, n. 41, $2007 . \quad$ Disponível em $<$ http://periodicos.ses.sp.bvs.br/scielo.php?script=sci_arttext\&pid=S151818122007000100003\&lng=pt\&nrm=iso >. acessado em 27 de março 2021.

FLORY, Nicole, LANG, Elvira V. Distress in the Radiology Waiting Room. Radiology, 260(1), $166-173,2011$

GUIRADO, Marlene. A Clínica Psicanalítica na Sombra do Discurso: diálogos com aulas de Dominique Maingueneau São Paulo: Casa do Psicólogo, 2000

HEIDEGGER, Martin. Tempo e Ser. In: Conferências e escritos filosóficos. Os pensadores (Heidegger). São Paulo: Editora Nova Cultural, 1999

HERITAGE, John, MCARTHUR, Amanda. The diagnostic moment: A study in US primary care. Social Science \& Medicine, 228, 262-271, 2019

HILLMAN, Alexandra. 'Why must I wait?' The performance of legitimacy in a hospital emergency department. Sociology of Health \& Illness Vol. 36 No. 4: 485-499, 2014

JANSZ, Jeroen. Masculine Identity and Restrictive Emotionality. In FISCHER, Agneta H. (Ed.), Gender and Emotion: Social Psychological Perspectives (p. 166-188). Cambridge: Cambridge University Press, 2000

JUTEL, Annemarie Goldstein. Putting a Name to it: diagnosis in contemporary society Baltimore: Johns Hopkins University Press, 2011 
JUTEL, Annemarie Goldstein. Beyond the Sociology of Diagnosis. Sociology Compass. 9/9, $841-852,2015$

KORNELSEN, Jude, ATKINS, Chloe, BROWNELL, Keith, WOOLLARD, Robert. The Meaning of Patient Experiences of Medically Unexplained Physical Symptoms. Qualitative health research, 26 (3), 367-376, 2015

MANSO, Maria Elisa Gonzalez. "A Gente não é uma doença, tem muita coisa por trás!" Narrativas de um grupo de pessoas portadoras de doenças crônicas sobre seu adoecimento. Tese de doutorado. PUCSP, 2014

MEIHY, José Carlos Sebe, HOLANDA, Fabíola. História Oral: como fazer, como pensar São Paulo: Contexto, 2007

MISHEL, Merle H. Reconceptualization of the Uncertainty in Illness Theory. Image: Journal of Nursing Scholarship, 22(4), 256-262, 1990

MORIN, Edgar. 'Resistir às incertezas é parte da Educação', diz Edgar Morin [Entrevista concedida a] Audrey Furlaneto. Rio de Janeiro, $O$ Globo. Disponível em: https://oglobo.globo.com/sociedade/resistir-as-incertezas-parte-da-educacao-dizedgar-morin-23723035?

MORSE, Janice M., JOHNSON, Joy L. (Eds). The Illness Experience: dimensions of suffering Newbury Park: Sage Publications Inc., 1991

NUNES, José Mendes, VENTURA, Teresa, ENCARNAÇÃO, Ricardo, PINTO, Patricia Rosado, SANTOS, Isabel. What do patients with medically unexplained physical symptoms (MUPS) think? A qualitative study. Mental Health in Family Medicine, 10, 67-79, 2013

PICARIELLO, Federica, ALI, Sheila, MOSS-MORRIS, Rona, CHALDER, Trudi. The Most Popular Terms for Medically Unexplained Symptoms: The View of CFS Patients. Journal of psychosomatic research, 78(5), 420-426, 2015

PORTELLI, Alessandro. What Makes Oral History Different. In PERKS, Robert, THOMSON, Alistair. (Eds.) The Oral History Reader. Taylor \& Francis e-Library, 2003

ROMANO, Belkiss Wilma. Princípios Para a Prática da Psicologia Clínica em Hospitais São Paulo: Casa do Psicólogo, 2007

SCHILLER, Paulo. A Vertigem da Imortalidade: segredos, doenças. São Paulo: Companhia das Letras, 2000

SOUZA, Robério Américo do Carmo. Narrativas Orais como Fontes para uma Compreensão Histórica da Experiência Vivida. Revista Maracanan, 17, 118-129, 2017

TEEL, Cynthia S., CARSON, Paula. Family Experiences in the Journey Through Dementia Diagnosis and Care. Journal of family nursing, 9(1), 38-58, 2003 
TRUNDLE, Catherine, SINGH, Ilina, BROER, Christian. Fighting to Be Heard: Contested Diagnoses. In JUTEL, Annemarie Goldstein, DEW, Kevin. (Eds.) Social issues in diagnosis: an introduction for students and clinicians. Johns Hopkins University Press. $165-182,2014$

Fernanda Tomie Icassati Suzuki Psicóloga Especialista em Psicologia da Saúde pela UNIFESP E-mail: fe.suzuki@gmail.com

Mariolga Teldeschi Lima Psicóloga e Neuropsicóloga da Interconsulta da Saúde Mental do Departamento de Psiquiatria da UNIFESP/HSP

Nadia Vitorino Vieira Psicóloga Pesquisadora no Centro de História e Filosofia das Ciências da Saúde (CeHFI) Unifesp/Campus São Paulo 